\title{
8
}

\section{Peptide receptor radionuclide therapy}

\author{
Jaap J.M. Teunissen* MD \\ Dik J. Kwekkeboom MD, PhD
}

Marion de Jong PhD

Jan-Paul Esser MD

Roelf Valkema MD, PhD

\section{Eric P. Krenning MD, PhD}

Professor and Head of the Department of Nuclear Medicine

Department of Nuclear Medicine, Erasmus MC,

Dr Molewaterplein 40, 3015 Rotterdam GD, The Netherlands

Peptide receptor radionuclide therapy is a new treatment modality for patients with inoperable or metastasised neuroendocrine gastroenteropancreatic tumours. After the successful implementation of somatostatin receptor scintigraphy in daily clinical practice, the next logical step was to increase the radiation dose of the administered radiolabelled somatostatin analogue in an attempt to induce tumour shrinkage. Since then, an increasing number of patients has been successfully treated with this approach, resulting in a substantial numbers of patient with objective tumour shrinkage. Serious sideeffects have been rare. This article reviews the effectiveness of the different radiolabelled somatostatin analogues used, the currently known side-effects and the survival data available. Furthermore, clinical issues, including indication and timing of therapy, are discussed. Finally, important directions for future research are briefly mentioned to illustrate that, although the currently available results already suggest a favourable outcome compared with other systemic therapies, new strategies are being developed to increase efficacy.

Key words: neuroendocrine tumours; carcinoid tumour; somatostatin receptors; radiotherapy; radionuclides.

\footnotetext{
* Corresponding author. Address: Department of Nuclear Medicine, Erasmus MC, Dr Molewaterplein 40, 3015 GD Rotterdam, The Netherlands. Tel.: + 3110463 4889; Fax: + 3 I 104635997.

E-mail addresses: j.teunissen@erasmusmc.nl (J.J.M. Teunissen), d.j.kwekkeboom@erasmusmc.nl (D. J. Kwekkeboom), m.hendriks-dejong@erasmusmc.nl (M. de Jong), j.esser@erasmusmc.nl (J.-P. Esser), r.valkema@erasmusmc.nl (R. Valkema), e.p.krenning@erasmusmc.nl (E.P. Krenning).
}

I52I-69|8/\$ - see front matter (C) 2005 Elsevier Ltd. All rights reserved. 
Somatostatin receptor (SSTR) scintigraphy, which was developed in the late 1980s, has become an important image modality in patients with SSTR-positive tumours. ${ }^{1,2}$ This is not only because of its high sensitivity for visualising somatostatin-positive tumours and thereby its ability to localise otherwise undetectable disease, but also because of the selection of known metastatic disease for peptide receptor radionuclide therapy (PRRT) with radiolabelled somatostatin analogues. This new modality of targeted therapy is very promising, especially in patients with inoperable or metastatic gastroenteropancreatic (GEP) tumours (i.e. gastrointestinal carcinoids and functioning and non-functioning pancreatic endocrine tumours).

\section{RADIONUCLIDES AND SOMATOSTATIN ANALOGUES IN PEPTIDE RECEPTOR RADIONUCLIDE THERAPY}

Several radiolabelled somatostatin analogues are currently used to treat patients with SSTR-positive metastasised GEP tumours. These conjugates all consist of a somatostatin analogue, such as octreotide or octreotate, a complexing moiety (or chelator) and a radionuclide. The chelator, which is attached to the somatostatin analogue, allows a stable connection between the analogue and the radionuclide. The basic principle of tumour-targeting after systemic administration of the conjugate involves binding to SSTRs, which are expressed on the cell surface of the tumour cell, followed by effective internalisation of the radionuclide-peptide complex. ${ }^{3-5}$ The emitted radiation can damage the DNA, which may subsequently lead to the induction of cell death. In clinical practice, different combinations of radionuclides and somatostatin analogues are used to target the SSTR-positive tumour. These analogues differ from each other in their affinity for the various SSTR subtypes. This variable affinity is important because it can have great influence on the clinical effectiveness of the radiolabelled somatostatin analogue. The available radionuclides and somatostatin analogues used will be discussed.

\section{Radionuclides in peptide receptor radionuclide therapy}

Indium ( $\left.{ }^{11} \mathrm{In}\right)$, yttrium $\left({ }^{90} \mathrm{Y}\right)$ and lutetium $\left({ }^{177} \mathrm{Lu}\right)$ have been the most frequently used radionuclides for targeted radiotherapy in the various clinical trials over the past decade. Differences in the physical properties of these radionuclides, which are important for the effectiveness of the therapy, relate to, for example, emitted particles, particle energy and tissue penetration range (Table I). ${ }^{\prime \prime}$ In, coupled via the chelator DTPA to D-Phe'-octreotide ([ ${ }^{\prime \prime}$ In-DTPA $\left.{ }^{0}\right]$ octreotide; ${ }^{\prime \prime}$ In-octreotide), was used in the first clinical trials in which patients with metastasised GEP tumours were treated with radiolabelled somatostatin analogues. ${ }^{6-8}$ Besides $\gamma$-radiation, which makes 1II In a suitable radionuclide for imaging, it emits both Auger and conversion electrons with a medium-to-short tissue penetration range $(0.02-10$ and $200-500 \mu \mathrm{m}$, respectively). In vitro PRRT studies with [ ${ }^{1 \prime \prime}$ In-DTPA ${ }^{0}$ ]octreotide showed that the therapeutic effect was dependent on internalisation, which enables the Auger electrons to reach the nucleus.' These results suggest that the Auger electrons and not the conversion electrons can be held responsible for the reported tumour responses with III In-labelled somatostatin analogues.

In an attempt to increase the efficacy of PRRT, clinical trials that followed used $\beta$-emitting radionuclides, such as ${ }^{90} \mathrm{Y}$ or ${ }^{177} \mathrm{Lu}$. Radionuclides emitting $\beta$-radiation have 
Table I. Physical characteristics of the radionuclides used in peptide receptor radionuclide therapy.

\begin{tabular}{|c|c|c|c|c|}
\hline Radionuclides & $\begin{array}{l}\text { Emitted } \\
\text { particle }\end{array}$ & $\begin{array}{l}\text { Particle energy } \\
\text { (mean keV) }\end{array}$ & $\begin{array}{l}\text { Maximum tissue penetration } \\
\text { range (approximate number } \\
\text { of cells } s^{\mathrm{a}} \text { ) }\end{array}$ & Half-life (days) \\
\hline \multirow[t]{3}{*}{ Indium (III $\ln )$} & $\begin{array}{l}\text { Auger } \\
\text { electrons }\end{array}$ & 3 and $19 \mathrm{keV}$ & $10 \mu \mathrm{m}(<\mathrm{I})$ & 2.8 \\
\hline & $\gamma$-radiation & $|7|$ and & & \\
\hline & & $245 \mathrm{keV}$ & & \\
\hline Yttrium $\left({ }^{90} \mathrm{Y}\right)$ & $\beta$-radiation & $935 \mathrm{keV}$ & $12 \mathrm{~mm}$ (approximately 600) & 2.7 \\
\hline \multirow[t]{3}{*}{ Lutetium $\left({ }^{177} \mathrm{Lu}\right)$} & $\beta$-radiation & $130 \mathrm{keV}$ & $2 \mathrm{~mm}$ (approximately 100) & 6.7 \\
\hline & $\gamma$-radiation & 113 and & & \\
\hline & & $208 \mathrm{keV}$ & & \\
\hline
\end{tabular}

greater therapeutic potential since the emitted particle range exceeds the cell diameter. ${ }^{10-12}$ Furthermore, the ability to irradiate neighbouring cells is an advantage with tumours, such as breast carcinomas, that are characterised by a heterogeneous SSTR tissue distribution, with regions of high density next to regions that lack receptor expression. ${ }^{13}$ As expected, the clinical and preclinical studies in which ${ }^{90} \mathrm{Y}-$ or ${ }^{177} \mathrm{Lu}-$ coupled somatostatin analogues were used demonstrated more effectiveness in terms of tumour shrinkage than was reported with somatostatin analogues coupled to ${ }^{11}$ In. ${ }^{14-17}$ O'Donoghue et al, ${ }^{12}$ who used a mathematical model to examine tumour curability and its relationship to tumour size for $22 \beta$-emitting radionuclides, calculated an optimal tumour diameter for cure of 34 and $2 \mathrm{~mm}$ for ${ }^{90} \mathrm{Y}$ and ${ }^{177} \mathrm{Lu}$, respectively.

With respect to these calculations, the preclinical studies by de Jong et al, ${ }^{14,18}$ in which Lewis rats bearing SSTR-positive pancreatic CA20948 tumours of different sizes $\left(0.1-15 \mathrm{~cm}^{2}\right)$ were treated with $\left[{ }^{177}\right.$ Lu-DOTA $\left.{ }^{0}, \mathrm{Tyr}^{3}\right]$ octreotate ( ${ }^{177}$ Lu-DOTATATE) and $\left[{ }^{90}\right.$ Y-DOTA ${ }^{0}$, Tyr $^{3}$ ]octreotide $\left({ }^{90}\right.$ Y-DOTATOC) are of special interest. After treatment with ${ }^{177}$ Lu-DOTATATE (total cumulative dose $555 \mathrm{MBq}$, maximum estimated tumour dose $60 \mathrm{~Gy}$ ), a higher cure rate was observed in the group of rats bearing small tumours $\left(\leq 1 \mathrm{~cm}^{2}\right)$ than in the rats bearing larger tumours $\left(\geq 1 \mathrm{~cm}^{2}\right.$, mean approximately $\left.5 \mathrm{~cm}^{2}\right)$. In contrast, treatment with a single dose of $370 \mathrm{MBq}$ ${ }^{90} \mathrm{Y}$-DOTATOC, leading up to a maximum of $60 \mathrm{~Gy}$ in the medium-sized $\left(3-9 \mathrm{~cm}^{2}\right)$ tumours, showed less cure within the group of rats bearing small $\left(\leq 1 \mathrm{~cm}^{2}\right)$ tumours compared with the rats bearing medium-sized tumours (Figure I). ${ }^{19}$ These results suggested that treatment with a combination of ${ }^{90} \mathrm{Y}$ - and ${ }^{177} \mathrm{Lu}$-labelled somatostatin analogues can be more effective in the treatment of multiple tumours that differ in size than can one of the analogues separately. Recently, de Jong et $\mathrm{al}^{20}$ reported the results of such a combination versus single analogue therapy. In rats bearing both a small $\left(<0.5 \mathrm{~cm}^{2}\right)$ and a large tumour $\left(7-9 \mathrm{~cm}^{2}\right)$, significantly better survival was observed after PRRT with the combination of $185 \mathrm{MBq}$ (half-dose) ${ }^{90} \mathrm{Y}$-DOTATOC and $278 \mathrm{MBq}$ (half-dose) ${ }^{177} \mathrm{Lu}$-DOTATATE than after a single full dose of $370 \mathrm{MBq}{ }^{90} \mathrm{Y}$-DOTATOC or $555 \mathrm{MBq}{ }^{177}$ Lu-DOTATATE.

To translate these results to the clinical setting with patients with GEP tumours, ${ }^{90}$ Y-labelled somatostatin analogues may be more effective in larger tumours, whereas ${ }^{177}$ Lu-labelled somatostatin analogues may be more effective in smaller tumours, with the combination of both radionuclides as the most suitable therapy for the clinical 


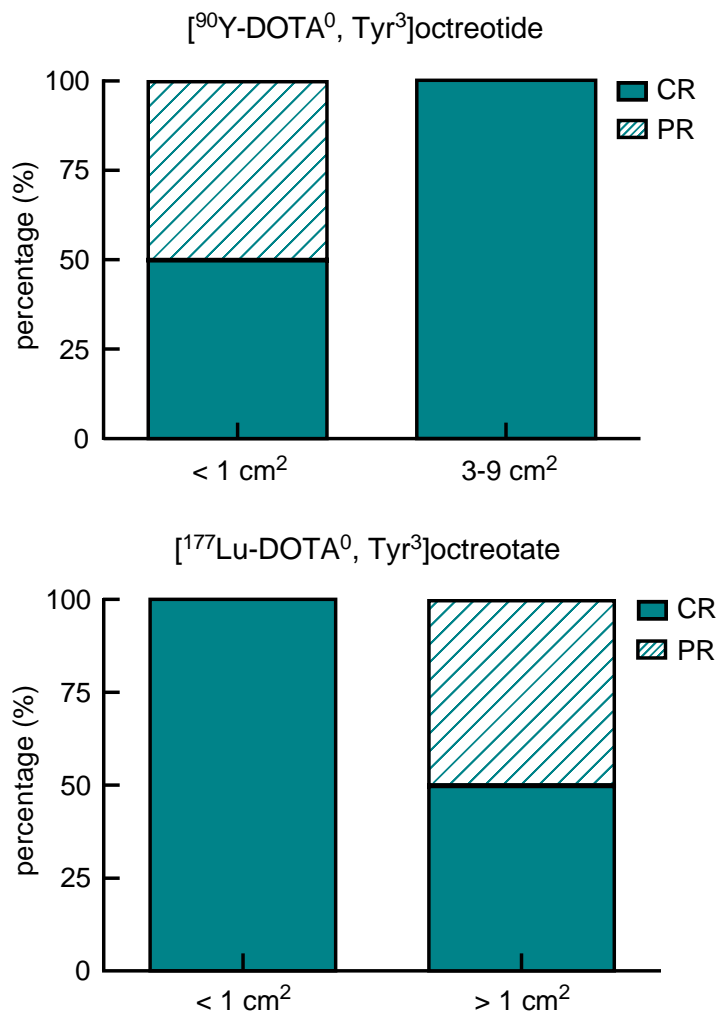

Figure I. Cure rate (expressed as percentage of cured rats) found in groups of rats bearing CA20948 tumours of different indicated sizes after treatment with $370 \mathrm{MBq}\left[{ }^{90} \mathrm{Y}-\mathrm{DOTA}{ }^{0}, \mathrm{Tyr}^{3}\right]$ octreotide or $555 \mathrm{MBq}\left[{ }^{177} \mathrm{Lu}^{-D O T A^{0}}, \mathrm{Tyr}^{3}\right.$ ]octreotate (maximum estimated tumour dose of $60 \mathrm{~Gy}$ for both treatments). $\mathrm{CR}$, complete response; PR, partial response. (Modified from de Jong et al. ${ }^{14}$ ).

situation in which most patients have tumour metastases varying in size. Unfortunately, randomised controlled clinical studies comparing the therapeutic efficacy of ${ }^{90} \mathrm{Y}$ and ${ }^{177}$ Lu somatostatin analogues or combination-based regimens are still lacking.

\section{Somatostatin analogues in peptide receptor radionuclide therapy}

The various ${ }^{111}$ In-, ${ }^{90} Y$ - or ${ }^{177}$ Lu-labelled somatostatin analogues differ in their affinity for the expressed SSTRs. Five human SSTR subtypes (SSTRI-SSTR5) that bind native human somatostatin (SSI4) and its high-affinity 28 amino acid precursor (SS28) have been cloned. ${ }^{2 \mathrm{I}-23}$ However, their affinities for synthetic somatostatin analogues differ considerably. The 'cold' analogue octreotide, which is frequently used to control symptoms related to hormone overproduction by GEP tumours, binds with high affinity to SSTR2 and with low affinity to SSTR3 and SSTR5, whereas it does not bind to SSTR I and SSTR 4. ${ }^{24,25}$ Furthermore, autoradiography studies by Reubi et al ${ }^{26}$ demonstrated that, after labelling octreotide, via DTPA, with ${ }^{11}$ In, the affinities to SSTR2 and SSTR5 were diminished (Table 2). However, despite the change in affinities, SSTR2 


\begin{tabular}{|c|c|c|c|c|c|}
\hline Peptides & hSSTRI & hSSTR2 & hSSTR3 & hSSTR4 & hSSTR5 \\
\hline Somatostatin-28 & $5.2 \pm 0.3(19)$ & $2.7 \pm 0.3(19)$ & $7.7 \pm 0.9(19)$ & $5.6 \pm 0.4(19)$ & $4.0 \pm 0.3(19)$ \\
\hline Octreotide & $>10,000(5)$ & $2.0 \pm 0.7(5)$ & $187 \pm 55$ & $>1,000(5)$ & $22 \pm 6(5)$ \\
\hline DTPA-octreotide & $>10,000(6)$ & $12 \pm 2(5)$ & $376 \pm 84(5)$ & $>1,000(5)$ & $299 \pm 50(6)$ \\
\hline IIIIn-octreotide & $>10,000(5)$ & $22 \pm 3.6(5)$ & $182 \pm 13(5)$ & $>1,000(5)$ & $237 \pm 52(5)$ \\
\hline DOTATOC & $>10,000(7)$ & $14 \pm 2.6(6)$ & $880 \pm 324(4)$ & $>1,000(6)$ & $393 \pm 84(6)$ \\
\hline${ }^{90} \mathrm{Y}$ - DOTATOC & $>10,000(4)$ & $1 \mathrm{II} \pm 1.7(6)$ & $389 \pm 135(5)$ & $>10,000(5)$ & $114 \pm 29(5)$ \\
\hline DOTALAN & $>10,000(7)$ & $26 \pm 3.4(6)$ & $771 \pm 229(6)$ & $>10,000(4)$ & $73 \pm 12(6)$ \\
\hline${ }^{90}$ Y-DOTALAN & $>10,000(3)$ & $23 \pm 5(4)$ & $290 \pm 105(4)$ & $>10,000$ & $16 \pm 3.4(4)$ \\
\hline DOTA-OC & $>10,000$ & $14 \pm 3(4)$ & $27 \pm 9(4)$ & $>1,000(4)$ & $103 \pm 39(3)$ \\
\hline${ }^{90}$ Y-DOTA-OC & $>10,000(5)$ & $20 \pm 2(5)$ & $27 \pm 8(4)$ & $>10,000(4)$ & $57 \pm 22(4)$ \\
\hline DTPA-Tyr ${ }^{3}-$ & $>10,000$ & $3.9 \pm I(4)$ & $>10,000(4)$ & $>1,000(4)$ & $>1,000(4)$ \\
\hline $\begin{array}{l}\text { octreotate } \\
\text { "11'In-DTPA-Tyr }{ }^{3}- \\
\text { octreotate }\end{array}$ & $>10,000(3)$ & $1.3 \pm 0.2(3)$ & $>10,000(3)$ & $433 \pm 16(3)$ & $>1,000(3)$ \\
\hline $\begin{array}{l}\text { DOTA-Tyr }{ }^{3} \text { - } \\
\text { octreotate }\end{array}$ & $>10,000(3)$ & $1.5 \pm 0.4(3)$ & $>1,000(3)$ & $453 \pm 176(3)$ & $547 \pm 160(3)$ \\
\hline $\begin{array}{l}{ }^{90} \text { Y-DOTA-Tyr }{ }^{3} \text { - } \\
\text { octreotate }\end{array}$ & $>10,000(3)$ & $1.6 \pm 0.4(3)$ & $>1,000(3)$ & $523 \pm 239$ & $187 \pm 50(3)$ \\
\hline
\end{tabular}

remains the receptor subtype for which $\left[{ }^{1 / 1}\right.$ In-DTPA $\left.{ }^{0}\right]$ octreotide has the highest affinity. Hofland et al ${ }^{27}$ demonstrated that the uptake of [ ${ }^{1{ }^{\prime \prime}}$ In-DTPA ${ }^{0}$ ]octreotide in the SSTR-positive organs of mice was predominantly determined by SSTR2. Moreover, John et $\mathrm{al}^{28}$ demonstrated that a positive $\left[{ }^{1 /}{ }^{\prime}\right.$ In-DTPA ${ }^{0}$ octreotide scintigram in patients with neuroendocrine tumours is mainly the result of SSTR2 expression, whereas SSTRI, SSTR3, SSTR4 and probably SSTR5 are less important.

Radiolabelled somatostatin analogues that had a higher affinity for SSTR2 than did II'In-octreotide, and were therefore potentially more effective for therapy, thus became available. Small structural changes in the radioligand molecule, for example a different radionuclide, chelator or peptide, revealed distinct differences in the binding properties of the analogue for the various SSTR subtypes (Table 2). ${ }^{26}$ In animal experiments, several 'II'In-labelled somatostatin analogues showed a higher specific uptake than ${ }^{\prime \prime \prime}$ In-labelled [DTPA ${ }^{0}$ ]octreotide in SSTR-positive organs. ${ }^{5}$ Furthermore, the analogue [DOTA ${ }^{0}, \mathrm{Tyr}^{3}$ ] octreotate has a ninefold higher affinity for SSTR2 compared with [DOTA ${ }^{0}, \mathrm{Tyr}^{3}$ ] octreotide, whereas the affinities for SSTR3 and SSTR5 were found to be lower. ${ }^{26}$ In line with the higher affinity for SSTR2, biodistribution studies on ${ }^{11}$ In-octreotide and ${ }^{177}$ Lu-DOTATATE scintigraphy showed a three- to fourfold higher tumour uptake in four out of five patients with somatostatin-positive tumours, of whom three had GEP tumours. ${ }^{29}$ As most GEP tumours are known to predominantly express SSTR2, all clinical studies selected a radiolabelled somatostatin analogue for PRRT with at least a high affinity for SSTR2. 


\section{CLINICAL STUDIES}

The outcome of several phase I and phase II PRRT studies, in which different radiolabelled somatostatin analogues were used, has been published. In addition, it has become apparent that the bone marrow and kidneys are the most important doselimiting organs in this type of therapy.

\section{$\left[{ }^{\prime \prime \prime}\right.$ In-DTPA $\left.{ }^{0}\right]$ octreotide}

The first radiolabelled somatostatin analogue therapy in GEP patients with advancedstage disease was based on the administration of high dosages of ${ }^{\prime \prime \prime}$ In-octreotide, which at that time was available for diagnostic purposes (Table 3). ${ }^{6,7,30,31}$ The total cumulative dose varied from 3.I GBq up to $160.0 \mathrm{GBq}$.

In a report by Valkema et al, ${ }^{6}$ in which the outcome of ${ }^{11}$ In-octreotide treatment in 50 patients with SSTR-positive tumours was reviewed, 15 out of the $26(58 \%)$ GEP patients had a stabilisation of their metastatic disease, and two out of $26(8 \%)$ showed minor remission, defined as a reduction in tumour size of between $25 \%$ and $50 \%$. Patients with stable disease and minor remission (17 out of $26 ; 65 \%$ ) were considered to have shown a beneficial therapeutic effect as all patients had documented progressive disease at study entry. In another report by Anthony et al, ${ }^{30} 2$ out of 26 (8\%) patients had a partial remission, whereas 21 out of $26(81 \%)$ had stable disease. Buscombe et a ${ }^{31}$ reported the outcome of 11 'In-octreotide therapy in 12 GEP patients treated with cumulative activities as high as $36.6 \mathrm{GBq}$. Seven out of the $12(58 \%)$ patients had stable disease 6 months after the last therapy, 2 (17\%) demonstrated partial remission and $3(25 \%)$ had progressive disease despite treatment.

Table 3. Peptide receptor radionuclide therapy with ${ }^{\prime \prime \prime}$ In-octreotide in patients with gastroenteropancreatic tumours.

\begin{tabular}{|c|c|c|c|c|c|c|c|}
\hline \multirow[b]{2}{*}{ Authors } & \multirow{2}{*}{$\begin{array}{l}\text { Number } \\
\text { of } \\
\text { patients }\end{array}$} & \multirow{2}{*}{$\begin{array}{l}\text { PD before } \\
\text { therapy }\end{array}$} & \multirow{2}{*}{$\begin{array}{l}\text { Cum dose } \\
\text { (GBq) }\end{array}$} & \multicolumn{4}{|c|}{ Response $^{a}$} \\
\hline & & & & PR & $M R^{b}$ & SD & PD \\
\hline $\begin{array}{l}\text { Valkema } \\
\text { et } \text { al }^{6}\end{array}$ & 26 & $\begin{array}{l}24 / 26(92 \%) \\
\text { (clinical and/ } \\
\text { or imaging } \\
\text { based) }\end{array}$ & $4.7-160.0$ & 0 & $2(8 \%)$ & 15 (58\%) & 9 (35\%) \\
\hline $\begin{array}{l}\text { Anthony } \\
\text { et } \mathrm{al}^{30}\end{array}$ & 26 & $\begin{array}{l}100 \% \text { (clinical } \\
\text { and/or ima- } \\
\text { ging based) }\end{array}$ & $6.7-46.6$ & 2 (8\%) & $N / I$ & 21 (8I\%) & 3 (II\%) \\
\hline $\begin{array}{l}\text { Buscombe } \\
\text { et } \mathrm{al}^{31}\end{array}$ & 12 & $\begin{array}{l}100 \% \text { (bio- } \\
\text { chemical } \\
\text { or imaging } \\
\text { based) }\end{array}$ & $3.1-36.6$ & $2(17 \%)$ & $N / I$ & 7 (58\%) & $3(25 \%)$ \\
\hline \multicolumn{8}{|c|}{$\begin{array}{l}\text { Cum dose, cumulative dose of }{ }^{\prime \prime \prime} \text { In-octreotide; N/I, not indicated. } \\
\text { a Criteria of tumour response: PR (partial remission), }>50 \% \text { reduction in tumour size; MR, xxxxx; SD } \\
\text { (stable disease), } \pm 25 \% \text { reduction or increase in tumour size; PD (progressive disease), }>25 \% \text { increase in } \\
\text { tumour size. } \\
\text { b Modification of SWOG criteria including MR (minor remission), between } 25 \text { and } 50 \% \text { reduction in } \\
\text { tumour size. }\end{array}$} \\
\hline
\end{tabular}


All the clinical PRRT studies reported encouraging and promising results, especially in terms of clinical benefit and biochemical responses. Reported cases of objective tumour shrinkage were, however, few. These outcomes suggested that the anti-tumour effect of ${ }^{11}$ In-octreotide is not ideal for PRRT, at least for visible GEP tumours. However, experimental data in rats have shown that high doses of ${ }^{11}$ In-octreotide can inhibit the growth of liver metastases after injecting SSTR2 receptor-positive tumour cells into the portal vein. ${ }^{32}$ These results suggest that PRRT with ${ }^{11}$ In-labelled analogues might be effective in the treatment of micro-metastases or metastatic spread during initial surgery. Clinical studies that could confirm these observations are, however, lacking.

\section{$\left[{ }^{90}\right.$ Y-DOTA ${ }^{0}$, Tyr $\left.^{3}\right]$ octreotide, $\left[{ }^{90} \mathrm{Y}\right.$-DOTA $]$ lanreotide and $\left[{ }^{90} \mathrm{Y}\right.$-DOTA ${ }^{0}$, Tyr $\left.^{3}\right]$ octreotate}

In the clinical trials that followed the PRRT with ${ }^{11}$ In-labelled analogues, ${ }^{90}$ Y-labelled analogues were used. A summary of these studies is shown in Table 4.

In 1998 , Otte et $\mathrm{al}^{33}$ reported the first results of 10 patients with SSTR-positive tumours treated with ${ }^{90} \mathrm{Y}$-DOTATOC. Two out of 10 patients had partial remission and six stable disease; in two patients, ${ }^{18} \mathrm{~F}$-deoxyglucose positron emission tomography, after a single dose of ${ }^{90} \mathrm{Y}$-DOTATOC, showed a substantial reduction of ${ }^{18} \mathrm{~F}$-deoxyglucose uptake in the tumour. In the studies that followed, the response rates (complete and partial remission) in patients with GEP tumours, who were treated with either $6.0 \mathrm{GBq} / \mathrm{m}^{2}$ or $7.4 \mathrm{GBq} / \mathrm{m}^{2}$, were 10 out $37(27 \%)$ and 8 out of $37(22 \%)$, respectively. ${ }^{16,34}$ To determine whether a decrease in the number of treatments, but at the same time maintaining the maximum cumulative dose of $7.4 \mathrm{GBq} / \mathrm{m}^{2}$ due to an increase of dosage per treatment, could increase the objective response another study was performed. ${ }^{35}$ Twelve out of 35 patients $(34 \%)$ had complete or partial remission, which indicated a higher percentage of tumour regression. No increase in the number of side-effects was reported.

Although these results suggested that an increase of dose, and as a consequence a decrease in the number of therapeutic injections, could be more beneficial, it must be stressed that this was not a randomised controlled trial and the number of treated patients was low. Nonetheless, the variation of protocol characteristics, such as the number of treatments, the doses per treatment or the length of treatment interval, are of great interest and may play an important role in the reported outcome of PRRT studies. Randomised controlled studies on the effects of these variables are therefore needed.

Clinical studies performed in Milan also used ${ }^{90} \mathrm{Y}$-DOTATOC to treat various SSTRpositive tumours. ${ }^{36-40}$ Recently, Bodei et al ${ }^{40}$ reported their experience with ${ }^{90}$ Y-DOTATOC, in which a total of 141 patients with various, somatostatin-positive tumours were treated. An objective response (complete or partial remission) of $26 \%$ was observed. More precisely, $23 \%$ of patients who had progressive disease before therapy (II 3 out of $14 \mathrm{I} ; 80 \%$ ) had complete or partial remission, whereas in the group with stable disease (28 out of $141 ; 20 \%$ ), $32 \%$ had complete or partial remission. Unfortunately, the specified treatment outcome according to tumour type was not given. It was, however, reported that most of the patients who had a favourable outcome had neuroendocrine GEP tumours. In a more detailed study from Milan, the outcome of therapy in 40 patients with SSTR-positive tumours was reported. ${ }^{39}$ The cumulative dose of ${ }^{90}$ Y-DOTATOC, which was given in two cycles, ranged from 5.9 to II.I GBq. In the group with GEP tumours, this therapy regimen resulted in partial 
Table 4. Peptide receptor radionuclide therapy with ${ }^{90} \mathrm{Y}$ - and ${ }^{177}$ Lu-labelled somatostatin analogues in patients with gastroenteropancreatic tumours.

\begin{tabular}{|c|c|c|c|c|c|c|c|c|}
\hline \multirow[b]{2}{*}{ Authors } & \multirow{2}{*}{$\begin{array}{c}\text { Number } \\
\text { of } \\
\text { patients }\end{array}$} & \multirow{2}{*}{$\begin{array}{c}\text { PD at } \\
\text { baseline }\end{array}$} & \multicolumn{6}{|c|}{ Response $^{a}$} \\
\hline & & & CR & PR & $M R^{b}$ & SD & PD & $C R+P R$ \\
\hline \multicolumn{9}{|c|}{ [90Y-DOTA0, Tyr3]octreotide } \\
\hline $\begin{array}{l}\text { Otte } \\
\text { et } \mathrm{al}^{48}\end{array}$ & 16 & $\mathrm{~N} / \mathrm{l}$ & 0 & I (6\%) & $N / I$ & 14 (88\%) & I (6\%) & $\begin{array}{l}1 / 16 \\
(6 \%)\end{array}$ \\
\hline $\begin{array}{l}\text { Waldherr } \\
\text { et } \mathrm{al}^{34}\end{array}$ & 37 & $\begin{array}{l}34 / 37 \\
(84 \%)\end{array}$ & I (3\%) & $9(24 \%)$ & $N / I$ & $23(62 \%)$ & $4(11 \%)$ & $\begin{array}{l}10 / 37 \\
(27 \%)\end{array}$ \\
\hline $\begin{array}{l}\text { Waldherr } \\
\text { et al }{ }^{16}\end{array}$ & 37 & $\begin{array}{l}37 / 37 \\
(100 \%)\end{array}$ & I (3\%) & $7(19 \%)$ & $N / I$ & $6(70 \%)$ & $3(8 \%)$ & $\begin{array}{l}8 / 37 \\
(22 \%)\end{array}$ \\
\hline $\begin{array}{l}\text { Waldherr } \\
\text { et } \mathrm{al}^{35}\end{array}$ & 35 & $\begin{array}{l}35 / 35 \\
(100 \%)\end{array}$ & $2(6 \%)$ & $10(29 \%)$ & $N / I$ & $19(54 \%)$ & $4(11 \%)$ & $\begin{array}{l}12 / 35 \\
(34 \%)\end{array}$ \\
\hline $\begin{array}{l}\text { Bodei } \\
\text { et } \mathrm{al}^{39}\end{array}$ & 21 & $\mathrm{~N} / \mathrm{I}$ & 0 & $6(29 \%)$ & $N / I$ & II (52\%) & $4(19 \%)$ & $\begin{array}{l}6 / 21 \\
(29 \%)\end{array}$ \\
\hline $\begin{array}{l}\text { Valkema } \\
\text { et } \mathrm{al}^{4 !}\end{array}$ & 54 & $\begin{array}{l}41 / 54^{c} \\
(76 \%)\end{array}$ & 0 & $4(7 \%)$ & $7(13 \%)$ & $33(61 \%)$ & $10(19 \%)$ & $\begin{array}{l}4 / 54 \\
(7 \%)\end{array}$ \\
\hline \multicolumn{9}{|c|}{ [90Y-DOTA]lanreotide } \\
\hline $\begin{array}{l}\text { Virgolini } \\
\text { et } \text { al }^{15}\end{array}$ & 39 & $\begin{array}{l}39 / 39 \\
(100 \%)\end{array}$ & 0 & 0 & $8(20 \%)$ & 17 (44\%) & $14(36 \%)$ & $\begin{array}{l}0 / 39 \\
(0 \%)\end{array}$ \\
\hline \multicolumn{9}{|c|}{ [90Y-DOTA0,Tyr3]octreotate } \\
\hline $\begin{array}{l}\text { Baum } \\
\text { et al }\end{array}$ & 75 & $\begin{array}{l}67 / 75 \\
(89 \%)\end{array}$ & 0 & $28(37 \%)$ & $N / I$ & $39(52 \%)$ & $8(11 \%)$ & $\begin{array}{l}28 / 75 \\
(37 \%)\end{array}$ \\
\hline \multicolumn{9}{|c|}{ [I 77Lu-DOTA0,Tyr3]octreotate } \\
\hline $\begin{array}{l}\text { Kwekke- } \\
\text { boom } \\
\text { et } \mathrm{al}^{45}\end{array}$ & 76 & $\begin{array}{l}29 / 76 \\
(38 \%)\end{array}$ & I (I\%) & $22(29 \%)$ & $9(12 \%)$ & $30(39 \%)$ & $14(18 \%)$ & $\begin{array}{l}23 / 76 \\
(30 \%)\end{array}$ \\
\hline $\begin{array}{l}\text { N/l, not in } \\
\text { a Criteri } \\
\text { remission) } \\
\text { size; PD ( } P \\
\text { b Modifi } \\
\text { tumour siz } \\
\text { c R. Valk }\end{array}$ & $\begin{array}{l}\text { cated. } \\
\text { of tumour } \\
50 \% \text { redu } \\
\text { ogressive di } \\
\text { tion of SW } \\
\text { na, person }\end{array}$ & $\begin{array}{l}\text { esponse ( } \\
\text { tion in tum } \\
\text { sease), }>2 \\
\text { J criteria }\end{array}$ & $\begin{array}{l}\text { NOG); } \\
\text { sur size; } \\
\% \text { increa } \\
\text { including } \\
\text { ation, } 20\end{array}$ & $\begin{array}{l}\text { (complete } \\
\text { (stable dis } \\
\text { in tumour } \\
\text { R (minor re }\end{array}$ & $\begin{array}{l}\text { emission), } \\
\text { ase), } \pm 25 \\
\text { ize. } \\
\text { mission), }\end{array}$ & $\begin{array}{l}\text { o evidence } \\
6 \text { reduction } \\
\text { etween } 25\end{array}$ & $\begin{array}{l}\text { of disease; } \\
\text { or increase } \\
\text { nd } 50 \% \text { red }\end{array}$ & $\begin{array}{l}\text { PR (partial } \\
\text { in tumour } \\
\text { uction in }\end{array}$ \\
\hline
\end{tabular}

remission in 6 out of 21 patients (29\%), whereas II out of 21 (52\%) had stable disease and $4 / 21$ (19\%) had progressive disease.

Valkema et $\mathrm{al}^{4 \mathrm{I}}$ reported the preliminary results of a multicentre phase I study performed in Rotterdam, Brussels and Tampa. The objective was to define the maximum tolerated single and four-cycle doses of ${ }^{90}$ Y-DOTATOC. ${ }^{6,11,14}$ Escalating doses up to $14.8 \mathrm{GBq} / \mathrm{m}^{2}$ in four doses or up to $9.3 \mathrm{GBq} / \mathrm{m}^{2}$ in a single dose were administered to a total of 60 patients. Four of the $54(7 \%)$ patients who were treated with their maximum allowed dose had partial remission, 7 out of 54 (13\%) had minor remission, and 33 out of $54(61 \%)$ showed stabilisation of their disease. Anti-tumour effect in terms of improvement of response, according to the SWOG (Southwest Oncology Group) tumour response criteria, including stable disease and minor remission in patients with progressive disease at the start of therapy, was reported as $65 \%{ }^{41}$ The median time to progression of that same group had not been reached at 26 months. $^{42}$ 
In a European multicentre study (MAURITIUS), another ${ }^{90}$ Y-labelled somatostatin analogue, ${ }^{90}$ Y-DOTA-lanreotide, was used to treat 39 GEP patients. The total cumulative dose ranged from $1.9 \mathrm{GBq}$ to $8.6 \mathrm{GBq}(50-232 \mathrm{mCi})$ of ${ }^{90}$ Y-DOTAlanreotide. ${ }^{15}$ Eight out of 39 (20\%) patients showed minor remission, and 17 out of 39 $(44 \%)$ had stable disease. The first results of the therapeutic efficacy in patients with SSTR-positive tumours with the somatostatin analogue $\left[{ }^{90} \mathrm{Y}^{-D O T A}{ }^{0}, \mathrm{Tyr}^{3}\right.$ ] octreotate ( ${ }^{90}$ Y-DOTATATE) were recently reported by Baum et al. ${ }^{43,44}$ Twenty-eight out of 75 (37\%) patients had partial remission, and 39 out of 75 (52\%) demonstrated stable disease after therapy. Therefore, ${ }^{90}$ Y-DOTATATE might also be a promising ${ }^{90}$ Y-labelled somatostatin analogue. Despite the differences in somatostatin analogues and protocols used in the various ${ }^{90}$ Y-based PRRT studies, the reported results of therapy in terms of complete and partial remission percentages, ranging up to $37 \%$ (Table 4), indicated an improvement in therapeutic effectiveness compared with the studies with III In-labelled octreotide.

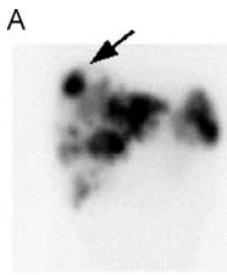

1st cycle

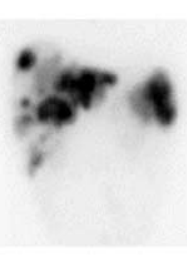

2nd cycle

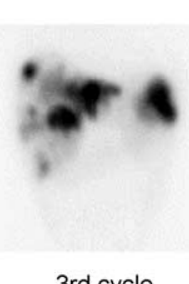

3rd cycle

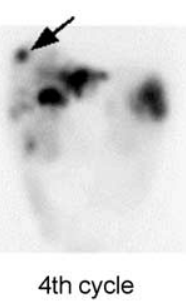

4th cycle
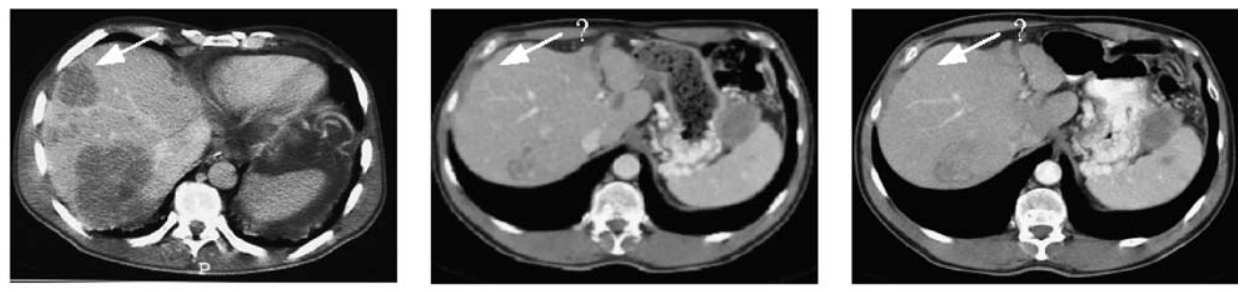

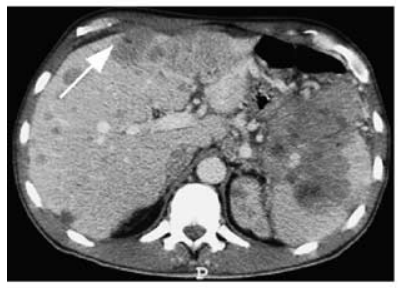

CT-scan pre-therapy

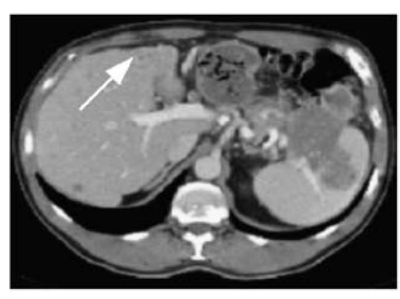

CT-scan 6 weeks after 4 th cycle

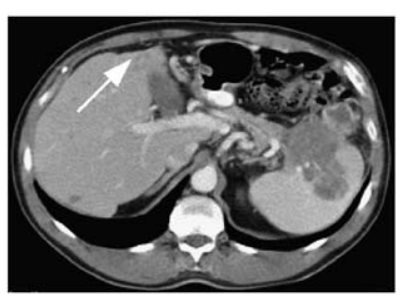

CT-scan 3 months after 4th cycle

Figure 2. Baseline and follow-up data of a patient with carcinoid with liver metastases. (A) Post-therapy scintigraphy after each cycle is shown (top row). Note the decrease of uptake of $\left[{ }^{177}\right.$ Lu-DOTA $^{0}$, $\mathrm{Tyr}^{3}$ ] octreotate on the last scintigraphy scan in comparison with the first (black arrows indicating the index lesion). At 3 and 6 months after four cycles of therapy, the patient had a partial remission ( $>50 \%$ decrease in tumour volume on computed tomography; white arrows indicate the index lesion) (bottom row). (B) Regression of the tumour mass was accompanied by a decrease in serum concentration of alkaline phosphatase (reference range 0-119 U/I), gamma-glutamyl transpeptidase (gamma-GT; reference range $0-49 \mathrm{U} / \mathrm{l})$ and the tumour marker chromogranin A (reference range $10-100 \mathrm{ng} / \mathrm{ml}$ ). 


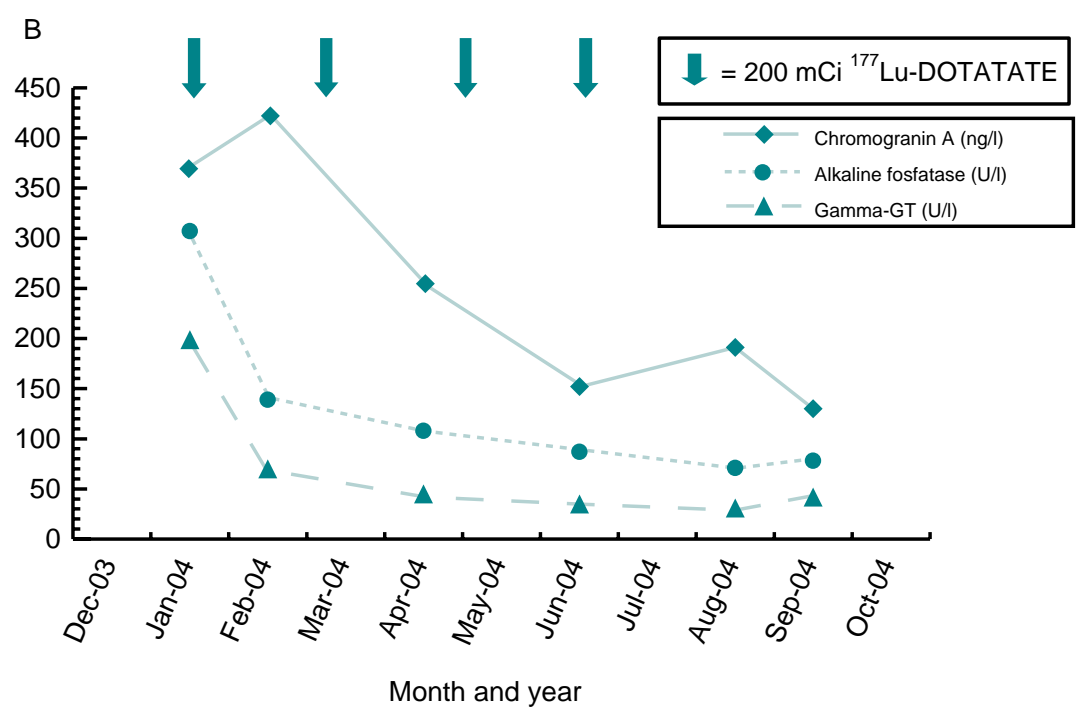

Figure 2 (continued)

\section{$\left[^{177}\right.$ Lu-DOTA $^{0}$, Tyr $\left.^{3}\right]$ octreotate}

The first results of $\left[{ }^{177}\right.$ Lu-DOTA ${ }^{0}$, Tyr $^{3}$ ]octreotate ( ${ }^{177}$ Lu-DOTATATE) therapy were described in a study of 35 patients with neuroendocrine GEP tumours, who had a follow-up of 3-6 months after receiving their final dose. ${ }^{17}$ Patients were treated with escalating dosages from 100 to 150 , and a maximum of $200, \mathrm{mCi}(3.7,5.6$ and $7.4 \mathrm{GBq}$, respectively) ${ }^{177}$ Lu-DOTATATE, up to a final cumulative dose of $600-800 \mathrm{mCi}$ (22.2-29.6 GBq), with treatment intervals of 6-9 weeks. The effects of the therapy on tumour size were evaluable in 34 patients. Three months after the final administration, a complete remission was found in one patient (3\%), a partial remission in $12(35 \%)$, stable disease in $14(41 \%)$ and progressive disease in seven (2l\%), including three patients who died during the treatment period.

In an update on this treatment in 76 patients with GEP tumours, ${ }^{45}$ complete remission was found in one patient (I\%), partial remission in 22 (29\%), minor remission in 9 (12\%), stable disease in 30 (40\%), and progressive disease in 14 patients (18\%). The effect of ${ }^{177}$ Lu-DOTATATE therapy on tumour size, uptake on post-therapy scintigraphy, liver enzymes and the tumour marker chromogranin $A$ in a patient who showed partial remission is shown in Figure 2. Six out of 32 patients who had induced stable disease or tumour regression after the therapy and were also evaluated after 12 months (mean 18 months from therapy start) developed progressive disease; in the other 26, the tumour response was unchanged. Median time to progression was not reached at 25 months from the beginning of therapy. In a more recent evaluation of response in a total of $13 \mid$ GEP tumour patients, these outcomes were confirmed, with a median time to progression of more than 36 months. ${ }^{46}$ 


\section{Comparison of the different treatments}

Treatment with ${ }^{90} \mathrm{Y}$ - and ${ }^{177} \mathrm{Lu}$-labelled somatostatin analogues is very encouraging in terms of tumour shrinkage. However, direct comparison to evaluate the optimal treatment remains difficult. Differences in treatment protocol, such as administered doses, dosing schemes and the tumour response criteria used, can be responsible for the observed differences in treatment outcome. Therefore, randomised controlled trials are necessary to define the optimal PRRT and treatment scheme.

\section{SIDE-EFFECTS AND RADIATION TOXICITY}

Adverse reactions observed after PRRT can be divided into direct side-effects and the more delayed effects of radiotoxicity. Direct effects commonly mentioned during and after therapy are nausea, vomiting and abdominal pain. ${ }^{17,30,34}$ In general, these sideeffects occur in a minority of patients and are easily treated with anti-emetics or pain medication. Mild hair loss was observed in patients treated with ${ }^{177}$ Lu-DOTATATE, but hair growth had normalised at follow-up 3-6 months after the last administration. ${ }^{17}$ Beside these mild side-effects, more serious toxicity may occur, especially to the bone

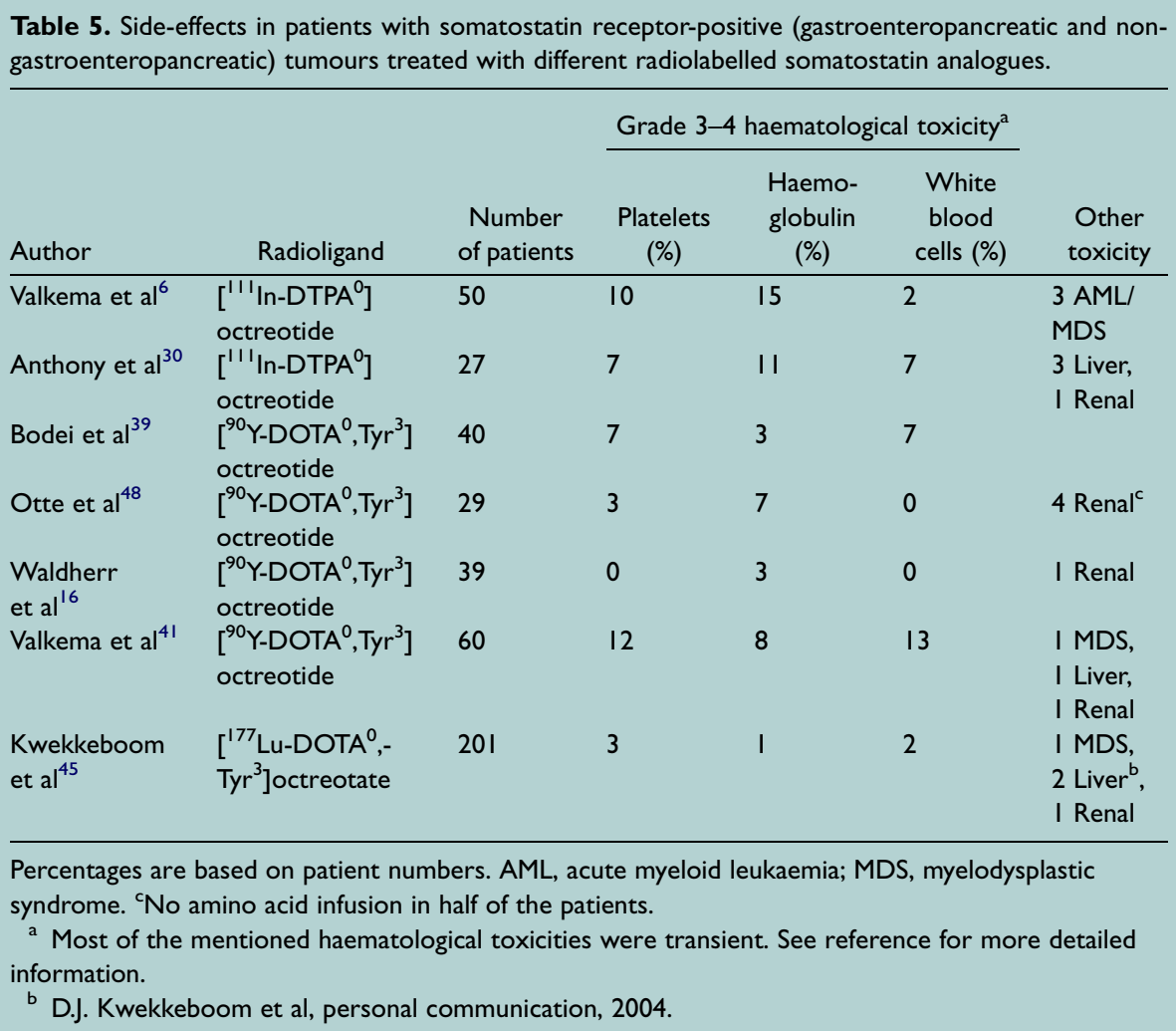


marrow, kidneys and liver. The reported percentages of these side-effects or toxicities are shown in Table 5.

\section{Haematological toxicity}

Haematological toxicities of grade 3-4 for haemoglobin, white blood cells and platelets were reported up to a maximum of I5\%. ${ }^{16,30,39,45,47,48}$ In general, the decrease in blood cell count was transient, and transfusion was only occasionally needed.

More serious side-effecs were reported from a clinical trial in which 50 patients were treated with ${ }^{11}$ In-octreotide. ${ }^{6}$ Leukaemia and myelodysplastic syndrome were reported in three patients who had been treated with total cumulative doses of over 2.7 $\mathrm{Ci} \mathrm{(100} \mathrm{GBq),} \mathrm{with} \mathrm{an} \mathrm{estimated} \mathrm{cumulative} \mathrm{bone} \mathrm{marrow} \mathrm{radiation} \mathrm{dose} \mathrm{of} \mathrm{about}$ $3 \mathrm{~Gy}$. One patient, who developed acute myeloid leukaemia 17 months after the first dose of "II In-octreotide, had had chemotherapy and treatment with interferon before PRRT. The other two patients, who had had no previous cytotoxic therapy, developed myelodysplastic syndrome after more than 3 years. None of the 44 patients who were treated with a cumulative dose lower than $100 \mathrm{GBq}$ developed myelodysplastic syndrome or leukaemia. In a phase I trial with ${ }^{90} \mathrm{Y}$-DOTATOC in which the objective was to define the maximal tolerated single and four-cycle doses, one patient had myelodysplastic syndrome 2 years after the start of PRRT; this patient had also had previous chemotherapy ${ }^{41}$ In the report by Kwekkeboom et al, ${ }^{45}$ who studied the patients treated with ${ }^{177}$ Lu-DOTATATE as PRRT, one patient in the whole group of patients who had been treated or were being treated up to that time (20I patients, 637 administrations) developed myelodysplastic syndrome. This patient had also previously received chemotherapy.

In summary, haematological toxicity in PRRT is in general mild and reversible, and the risk of developing myelodysplastic syndrome or leukaemia is low if certain dosing limits are respected.

\section{Renal toxicity}

Chelated somatostatin analogues are cleared predominantly by the kidneys. An accumulation and retention of these analogues within the kidney occurs but is not SSTR mediated. ${ }^{49}$ Because of the rapid clearance, [ [ ${ }^{11}$ In-DTPA ${ }^{0}$ ]octreotide can be safely applied for diagnostic use without any damage to the kidneys. ${ }^{1,50}$ For therapeutic use, however, the renal accumulation and the relatively long renal effective half-life of the radiopharmaceutical can be dose-limiting. In external beam radiation therapy, renal absorbed doses of $23 \mathrm{~Gy}$ (fractions of $2 \mathrm{~Gy}$ ) may cause nephropathy in $5 \%$ of patients in 5 years, whereas $28 \mathrm{~Gy}$ leads to a $50 \%$ risk over the same period. ${ }^{51}$ However, since PRRT is applied as continuous low-dose radiation with intracellular accumulation, a maximum cumulative dose limit of $23 \mathrm{~Gy}$ may not be applicable.

The first reports on acute (6-12 months after radiation exposure) and late (I-5 years after exposure) renal side-effects appeared after the use of ${ }^{90}$ Y-DOTATOC in various clinical trials. ${ }^{33,52-54}$ The results suggested that a cumulative dose of ${ }^{90}$ Y-DOTATOC of more than $7.4 \mathrm{GBq} / \mathrm{m}^{2}$ might be a risk factor for renal insufficiency. ${ }^{33}$ However, some years later, a case report of a patient who developed late-onset renal insufficiency with a total cumulative dose of less than $7.4 \mathrm{GBg} / \mathrm{m}^{2}$ indicated that even less radiation can cause renal damage at a later time point. ${ }^{53}$ In contrast, no renal toxicity was found in patients treated with [ ${ }^{111}$ In-DTPA ${ }^{0}$ octreotide. ${ }^{6}$ 
The difference between ${ }^{11}$ IIn and ${ }^{90} Y$ with regard to the induction of radiation nephropathy may be explained by the difference in the particle range emitted $(10 \mu \mathrm{m}$ versus approximately $12 \mathrm{~mm}$, respectively). The Auger electrons emitted by ${ }^{\prime \prime} \mathrm{In}$ within the tubular cells do not reach the radiosensitive glomeruli. This particle range advantage might also be the reason why only one patient of a group of $20 \mathrm{I}$ patients treated with ${ }^{177}$ Lu-DOTATATE developed renal failure. ${ }^{45}$ Although the number of patients reported with radiation nephropathy was relatively low, and the potential benefit for the patients outweighed the risk of occurrence of this severe complication, it became clear that PRRT-induced radiation nephropathy was difficult to predict with the currently applied maximum cumulative dose limits.

Two recent studies in which patients were treated with ${ }^{90}$ Y-DOTATOC provided more insight into individual kidney dosimetry and its importance in PRRT. ${ }^{55,56}$ These studies indicated that, apart from the total renal radiation dose, the dose volume, fractionation rate and clinical parameters of hypertension, diabetes and age are relevant risk factors for the development of a loss of renal function.

Kidney protection methods to prevent damage to the kidney from high absorbed doses with each administration are obviously of importance. The most important method currently used to reduce the renal uptake of radioactivity in PRRT is the use of amino acid solutions, which can be easily co-administered during therapy. Preclinical studies have shown that the infusion of positively charged amino acids, mainly L-lysine and L-arginine, are able to reduce the tubular reabsorption of radiolabelled somatostatin analogues in rats. ${ }^{57}$ Clinical studies have proved that co-infusion with a combination of the L-lysine and L-arginine or a mixed amino acid solution on the day of therapy led to a reduction in renal uptake of between 20 and $47 \%{ }^{29,39,58,59}$ Higher doses of amino acids are more effective but have the disadvantage of inducing a higher incidence of side-effects, such as nausea, vomiting and, especially with higher doses of L-lysine, hyperkalaemia. ${ }^{59,60}$

\section{Liver toxicity}

Most patients treated with PRRT in the clinical trials studied had liver metastases. The extent of liver involvement ranged from a single lesion to diffuse liver involvement with pronounced hepatomegaly. It is therefore not unlikely that PRRT can induce hepatocellular radiation injury. In clinical practice, however, it may be difficult to distinguish an increase of liver function parameters induced by radiation from a subtle progression of liver metastases.

Anthony et $\mathrm{al}^{30}$ reported three patients (from a total of 27), treated with II' In-octreotide, in whom a temporary increase in liver function parameters (grade 3 liver toxicity on World Health Organization toxicity grading) was observed. All three patients had a tumour replacement of more than $75 \%$ of their hepatic parenchyma and treatment-associated necrosis on the computed tomography scans. In patients with less extensive liver disease, changes in liver function parameters did not occur.

A significant increase in liver function parameters after the administration of ${ }^{90} \mathrm{Y}$-DOTATOC was reported in two studies. ${ }^{41,61}$ Valkema et al ${ }^{41}$ reported one transient grade 3 toxicity in a group of 60 patients treated with ${ }^{90}$ Y-DOTATOC (phase I study). In another study, 15 patients with proven liver metastases (of whom 12 had extensive liver involvement, defined as $25 \%$ or more) from neuroendocrine tumours were treated with three cycles of $120 \mathrm{mCi}(4.4 \mathrm{GBq})$ each. ${ }^{61}$ In only four of these 15 patients, one or more of the three liver enzymes that were measured-serum 
aspartate aminotransferase, alanine aminotransferase and alkaline phosphataseincreased-increased at least one grade, according to the World Health Organization common toxicity criteria, from baseline to final follow-up measurement (4-6 weeks post cycle 3). It was concluded that patients with diffuse SSTR-positive hepatic metastases could be treated with a cumulative administered activity of $360 \mathrm{mCi}$ ( $13.2 \mathrm{GBq})$ of ${ }^{90}$ Y-DOTATOC with only a small chance of developing mild acute or subacute hepatic injury.

In the group of patients treated with ${ }^{177}$ Lu-DOTATATE, significantly increased liver function parameters (grade 4 liver toxicity) was evident in two patients after the first cycle of treatment (D.J. Kwekkeboom, personal communication, 2004). One patient, who suffered from a rapidly growing neuroendocrine tumour with extensive liver involvement, clinically progressed to liver failure within 3 weeks and died shortly thereafter. Whether the aggressive nature of the tumour or the PRRT-induced toxicity led to this fatal condition remains unclear. The other patient, who after the first therapy developed dyspnoea, acute abdominal pain and increased liver function parameters, was hospitalised for several weeks. Gradually, the liver function parameters and hyperbilirubinaemia returned to pre-therapy levels. Treatment with ${ }^{177}$ Lu-DOTATATE was continued for 6 months after the first therapy with a reduced dose of $1.9 \mathrm{GBq}$ followed by a third administration of 4.I GBq without any acute side-effects.

\section{CLINICAL PRACTICE}

In patients with metastasised GEP tumours, for whom surgery is no longer an option, PRRT can be an effective alternative therapeutic modality with limited side-effects. The results in terms of tumour volume reduction, as shown in the different clinical trials, are very encouraging and seem to compare favourably with chemotherapy. No randomised controlled study has, however, been performed to confirm this.

Although proven effective in a substantial percentage of patients, PRRT has not been widely recognised as alternative systemic therapy. Instead, the 'wait-and-see' approach often remains the mainstay of initial management in patients with unresectable disease. The rationale for this approach is found in the natural history of well-differentiated GEP tumours not receiving treatment, in which tumours can be indolent for many years and the well-being of patients, even with metastasised tumours, can be unchanged for many years. However, the reported studies on PRRT clearly indicate that patients with documented progressive disease or a substantial increase in symptoms can benefit from this therapy. The recognition of the possible benefit of PRRT for patients with GEP tumours is increasing, but its implementation within the whole therapeutic array is rather poor. Factors that contribute to this include the fact that PRRT is a relatively new therapeutic modality, the lack of approved radiopharmaceuticals, which is in part related to increased governmental demands, and therapy-related costs.

\section{Indications for peptide receptor radionuclide therapy}

Candidates for PRRT are those patients with inoperable GEP tumours who have progressive disease or symptomatology that is difficult to manage with medication. If it is agreed that the malignancy is inoperable, the tumour has to be SSTR-positive, based on tumour uptake on "II In-octreotide scintigraphy. Furthermore, the amount of tumour uptake has to be equal to or higher than that of normal liver tissue 


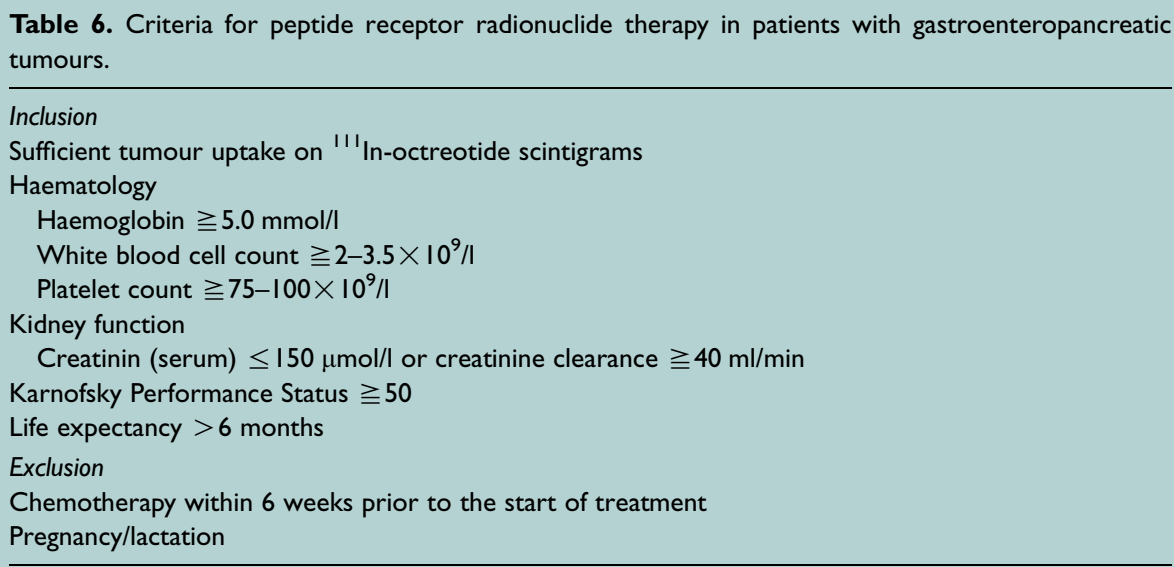

(according to criteria previously described by Krenning et al). ${ }^{10}$ High uptake during III In-octreotide scintigraphy has been shown to be correlated with tumour regression after PRRT. ${ }^{17}$ Additionally, because of the radiation to the bone marrow and the risk of temporary bone marrow suppression, patients need to fulfil certain minimal haematological criteria. Kidney function has to be determined before therapy to exclude patients with signs of impending renal failure (glomerular filtration rate $<40 \mathrm{ml} /$ minute). The presence of bone metastases, which occur in a minority of patients, is no exclusion criterion. As a rule, if a tumour response occurs, all tumour sites decrease in size. However, cystic and bone lesions seem to respond in a more protracted way than the more common, solid liver metastases. Up until now, no systematic study has been performed to address the issue of a possible differential response of metastases based on their location. The full patient selection criteria are summarised in Table 6.

\section{Timing of therapy}

There is currently no consensus about when to start PRRT in patients with GEP tumours. The stage of disease at which the diagnosis is made is highly variable and ranges from a localised, non-metastatic primary tumour to more advanced or end-stage disease with hepatomegaly and ascites. In a recent report in which the relationship between delay of diagnosis, extent of disease and survival in 115 patients with carcinoid was studied, a mean delay in the diagnosis of 66 months was found. ${ }^{62}$ It was concluded that the diagnosis of carcinoid is difficult, and therefore a delay of diagnosis by physicians is common. Strikingly, the delay of the diagnosis did not correlate with the extent of the disease. However, the extent of the disease did correlate with survival. Patients with primary tumours and lymph node metastases were less likely to die of carcinoid disease than patients with hepatic metastases, carcinomatosis or extraabdominal metastases.

Unfortunately, reports on PRRTwith explicit survival data are few. In the multicentre trial with ${ }^{11}$ In-octreotide, ${ }^{6}$ it was reported that PRRT for end-stage patients with a higher tumour burden was less likely to have a favourable outcome than for patients with lower tumour burden or in a better general condition. Survival data in a group of 
27 patients treated with ${ }^{11}$ In-octreotide presented by Anthony et al ${ }^{30}$ suggested a survival benefit in patients treated with ${ }^{\prime \prime \prime}$ In-octreotide. The number of patients studied was, however, low, and the survival data of the treated group were compared with data from a historical control group. In the studies with ${ }^{177}$ Lu-DOTATATE, it was suggested that, because of the high success rate of the therapy, the low incidence of side-effecs and the high median time to progression ( $>36$ months), its use can be advocated in patients with metastasised, unresectable GEP tumours without waiting for tumour progression. ${ }^{17,63}$

Another argument in favour of early treatment is that neuroendocrine tumours can dedifferentiate in the course of the disease and thereby lose the expression of SSTRs. Treatment with radiolabelled somatostatin analogues will then be impossible. ${ }^{17}$ However, whether early treatment would benefit patients with metastasised, unresectable GEP tumours in terms of longer survival remains to be studied and should imply randomisation into groups with and without PRRT. At this moment, when there seems to be proof that PRRT is an effective therapy, such a survival study seems unethical.

Another issue, regarding the question whether we should treat patients with PRRT or not at an early stage of the disease, is the benefit in terms of clinical response and quality of life. Not all studies address this issue. There is, however, a growing awareness of its importance in clinical oncology trials, especially in therapies for which cure is not

$\begin{array}{cccc}\star & * & \text { NS } & * * \\ \mathrm{n}=50 & \mathrm{n}=24 & \mathrm{n}=19 & \mathrm{n}=6 \\ \Delta 9.2 & \Delta 10.5 & \Delta 3.2 & \Delta 23.6\end{array}$

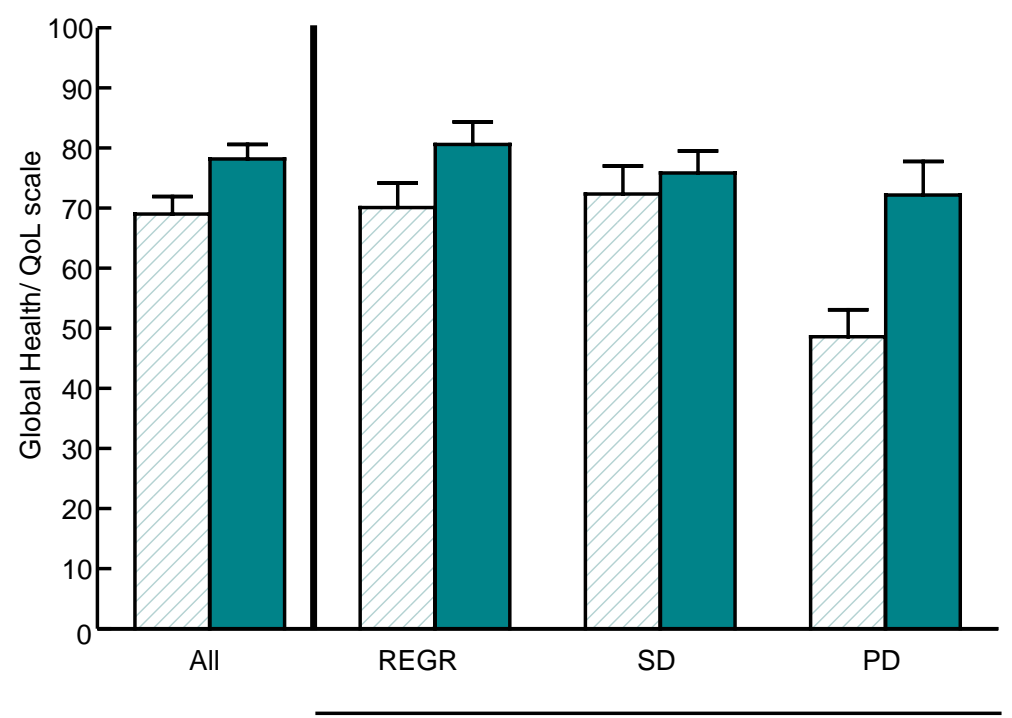

Groups

Figure 3. Global health/quality of life scale scores of all the patients $(n=50)$ and the different outcome groups according to tumour evaluation before (hatched bars) and 3 months after (grey bars) ${ }^{177}$ Lu-octreotate therapy. REGR, regression (complete, partial and minor remission); SD, stable disease; PD, progressive disease. Standard errors of the mean are shown; $* P<0.05 ; * * P<0.01$; NS, not significant (two-sided analysis of variance; $P<0.05$ was considered significant). (Modified from Teunissen et al. ${ }^{66}$ ). 
the primary goal and survival gains are low or unknown. ${ }^{64}$ As a consequence, the more recent PRRT reports have included data on the clinical effectiveness of therapy. Two studies with ${ }^{90}$ Y-DOTATOC provided evidence for a favourable clinical response in 60 $70 \%$ of the patients. ${ }^{47,65}$ In patients treated with ${ }^{177}$ Lu-DOTATATE, quality of life assessment showed a significant improvement in the global health/quality of life score $(\Delta$ score +9.2 , scale range $0-100, P<0.01$ ), especially in those patients with proven tumour regression $(\Delta$ score $+10.5, P<0.05)$ (Figure 3$).{ }^{66}$ Although the assessment methods for identifying clinical changes differ in these studies, the combined results suggest that patients may experience a clinical benefit from PRRT.

\section{FUTURE DEVELOPMENTS}

A direction of future research to improve current PRRT for GEP tumours includes the development of new stable somatostatin analogues with a high affinity for the different SSTR subtypes. The new analogue [DOTA ${ }^{0}$ - I-naphthyl ${ }^{3}$ ] octreotide (DOTANOC), for example, is an analogue that has a high affinity for SSTR2, SSTR3 and SSTR5. ${ }^{67}$ It might therefore be a promising analogue to be used for treatment of patients with tumours that not bear only SSTR2, but also express SSTR3 and/or SSTR5. Furthermore, combined treatment with different radiolabelled somatostatin analogues, analogous to the favourable response with combinational chemotherapy in solid tumours compared with single-agent therapy, is of great interest. This approach will of course be limited by the combined toxicity of the radiolabelled peptides. Preclinical PRRT studies with ${ }^{90} \mathrm{Y}$ DOTATOC and ${ }^{177}$ Lu-DOTATATE indicate that there is an optimal tumour size in terms of the efficacy of tumour reduction for each radionuclide. As most patients have metastatic disease with tumours of different sizes, combination PRRT could achieve higher cure rates compared with single-agent therapy.

Higher cure rates are possible when the density of expressed SSTRs is enhanced. In vitro and in vivo studies show that the irradiation of neuroendocrine AR42J (rat pancreatic tumour) cells can upregulate the expression of SSTR2 and gastrin receptors. ${ }^{68}$ PRRT after the upregulated expression of SSTR2 may lead to a higher uptake of the radiolabelled peptide and consequently a higher therapeutic efficacy.

Most research in PRRT is focused on the different SSTR subtypes. Neuroendocrine tumours may, however, coexpress other tumour-specific peptides, such as vasoactive intestinal peptide, cholecystokin, bombesin and GLP-I receptors. ${ }^{69}$ The concomitant expression of these receptors could be used in the future in a multireceptor PRRT to target more efficiently GEP tumours in each patient individually. This approach could, especially in tumours with a heterogeneous or even a reciprocal receptor distribution, be very favourable in terms of achieving a more homogenous distribution of the absorbed radiation dose within the tumour mass.

The combination of PRRT with surgery and/or chemotherapy as a multimodality treatment strategy is of interest and requires the start of randomised trials to prove whether current results can be improved. Studies that can also be considered are the use of PRRT combined with surgery in an adjuvant setting to irradiate occult metastases, or PRRT as debulking therapy followed by surgery in patients with inoperable but limited local disease. External beam radiotherapy in combination with chemotherapy such as gemcitabine, which is a known potent radiation sensitiser, has been shown to have favourable effects in patients with non-small-cell lung cancer. ${ }^{70}$ 
Although the patients were treated with external radiotherapy, gemcitabine and other radiosensitising agents with concurrent PRRT might prove effective in the future.

\section{SUMMARY}

PRRT holds great promise for the future regarding the treatment of various cancers. Using radiolabelled peptides, which bind with high affinity to specific receptors on cancer cells, it is possible to target the cancer efficiently. In GEP tumours, radiolabelled somatostatin analogue therapy has been proven to be effective. Dose-limiting organs are the bone marrow and the kidneys. With the currently used maximum allowed dose, PRRT is relatively safe, and serious side-effects are rare. It is impossible to conclude from the available literature which radiolabelled somatostatin analogue can be regarded as the most effective therapy. Also, the development of therapy strategies with combinations of different radionuclides, which is underway, is of interest as these strategies may in future provide an increase in therapeutic efficacy.

\section{Practice points}

- PRRT with $\beta$-emitting agents such as ${ }^{90} \mathrm{Y}$ and ${ }^{177} \mathrm{Lu}$ can induce tumour shrinkage in patients with SSTR-positive GEP tumours

- octreotide scintigraphy is used to select candidates for PRRT

- a high uptake during octreotide scintigraphy is correlated with a favourable outcome of PRRT

- the co-administration of amino acids during PRRT is essential to minimise the risk of renal toxicity

- blood examination before each cycle of PRRT is necessary as bone marrow suppression is a known risk of PRRT

\section{Research agenda}

The following areas are of interest in optimising PRRT:

- the development of new somatostatin analogues with a high affinity for different SSTR subtypes

- randomised controlled (multicentre) trials to compare the therapeutic efficacy of ${ }^{90} \mathrm{Y}$ - and ${ }^{177} \mathrm{Lu}$-labelled somatostatin analogues, and their use in combination

- the development of different peptide analogues with a high affinity

- the implementation of multimodality treatment strategies:

- surgery with adjuvant PRRT

- PRRT for debulking before surgery

- chemotherapy as a radiosensitiser for PRRT

- methods to upregulate the expression of SSTRs in vivo

- the reduction of kidney and bone marrow uptake 


\section{REFERENCES}

*I. Krenning EP, Kwekkeboom DJ, Bakker WH et al. Somatostatin receptor scintigraphy with [I I I In-DTPAD-Phel]- and [ I23I-Tyr3]-octreotide: the Rotterdam experience with more than 1000 patients. Eur J Nucl Med 1993; 20: 7I6-73I.

2. Kwekkeboom D, Krenning EP \& de Jong M. Peptide receptor imaging and therapy. J Nucl Med 2000; 4I: 1704-17|3.

3. Andersson $\mathrm{P}$, Forssell-Aronsson $\mathrm{E}$, Johanson $\mathrm{V}$ et al. Internalization of indium-III into human neuroendocrine tumor cells after incubation with indium-I I I-DTPA-D-Phel-octreotide. J Nucl Med 1996; 37: 2002-2006.

4. Hofland LJ, van Koetsveld PM \& Waaijers M. Internalization of the radioiodinated somatostatin analog [125I-Tyr3]octreotide by mouse and human pituitary tumor cells: increase by unlabeled octreotide. Endocrinology 1995; 136: 3698-3706.

5. de Jong M, Breeman WA, Bakker WH et al. Comparison of (I I I)In-labeled somatostatin analogues for tumor scintigraphy and radionuclide therapy. Cancer Res 1998; 58: 437-44I.

*6. Valkema R, De Jong M, Bakker WH et al. Phase I study of peptide receptor radionuclide therapy with [InDTPA]octreotide: the Rotterdam experience. Semin Nucl Med 2002; 32: II0-122.

7. McCarthy KE, Woltering EA \& Anthony LB. In situ radiotherapy with I I I In-pentetreotid. State of the art and perspectives. Q J Nucl Med 2000; 44: 88-95.

8. Krenning EP, Kooij PP, Bakker WH et al. Radiotherapy with a radiolabeled somatostatin analogue, [I I I lnDTPA-D-Phel]-octreotide. A case history. Ann N Y Acad Sci 1994; 733: 496-506.

9. Capello A, Krenning EP, Breeman WA et al. Peptide receptor radionuclide therapy in vitro using [ I I I lnDTPA0]octreotide. J Nucl Med 2003; 44: 98-104.

10. Krenning EP, de Jong M, Kooij PP et al. Radiolabelled somatostatin analogue(s) for peptide receptor scintigraphy and radionuclide therapy. Ann Oncol 1999; 10 (supplement 2): S23-S29.

II. Smith MC, Liu J, Chen T et al. OctreoTher: ongoing early clinical development of a somatostatinreceptor-targeted radionuclide antineoplastic therapy. Digestion 2000; 62(supplement I): 69-72.

12. O'Donoghue JA, Bardies M \& Wheldon TE. Relationships between tumor size and curability for uniformly targeted therapy with beta-emitting radionuclides. J Nucl Med 1995; 36: 1902-1909.

13. Reubi JC, Waser B, Foekens JA et al. Somatostatin receptor incidence and distribution in breast cancer using receptor autoradiography: relationship to EGF receptors. Int J Cancer 1990; 46: 4I6-420.

*14. de Jong $\mathrm{R}$, Valkema $\mathrm{F}$, Jamar $\mathrm{R}$ et al. Somatostatin receptor-targeted radionuclide therapy of tumors: preclinical and clinical findings. Semin Nucl Med 2002; 32: I33-140.

15. Virgolini I, Britton K, Buscombe J et al. In- and Y-DOTA-lanreotide: results and implications of the MAURITIUS trial. Semin Nucl Med 2002; 32: I48-I55.

16. Waldherr C, Pless M, Maecke HR et al. Tumor response and clinical benefit in neuroendocrine tumors after 7.4 GBq (90)Y-DOTATOC. J Nucl Med 2002; 43: 610-616.

*I7. Kwekkeboom DJ, Bakker WH, Kam BL et al. Treatment of patients with gastro-entero-pancreatic (GEP) tumours with the novel radiolabelled somatostatin analogue [(I77)Lu-DOTA(0),Tyr(3)]octreotate. Eur J Nucl Med Mol Imaging 2003; 30: 4I7-422.

18. de Jong M, Breeman WA, Bernard BF et al. Receptor-targeted radionuclide therapy using radiolabelled somatostatin analogues: tumour size versus curability. J Nucl Med 200 I; 28: 1026. (abstract).

19. de Jong M, Breeman WA, Bernard BF et al. Tumor response after [(90)Y-DOTA(0), Tyr(3)]octreotide radionuclide therapy in a transplantable rat tumor model is dependent on tumor size. J Nucl Med 200I; 42: $184 \mid-1846$.

20. de Jong M, Breeman WAP, Valkema $R$ et al. Combination radionuclide therapy using $177 \mathrm{Lu}-$ and $90 \mathrm{Y}-$ labeled somatostatin analogs. J Nucl Med 2005; 46: I3S-I7S.

2I. Rohrer L, Raulf F, Bruns $\mathrm{C}$ et al. Cloning and characterization of a fourth human somatostatin receptor. Proc Natl Acad Sci USA 1993; 90: 4196-4200.

22. Panetta R, Greenwood MT, Warszynska A et al. Molecular cloning, functional characterization, and chromosomal localization of a human somatostatin receptor (somatostatin receptor type 5) with preferential affinity for somatostatin-28. Mol Pharmacol 1994; 45: 4I7-427. 
23. Yamada Y, Post SR, Wang K et al. Cloning and functional characterization of a family of human and mouse somatostatin receptors expressed in brain, gastrointestinal tract, and kidney. Proc Natl Acad Sci USA 1992; 89: 25I-255.

24. Bruno JF \& Berelowitz M. Somatostatin teceptors: orphan that found family and function. Mol Cell Neurosci 1993; 4: 307-309.

25. Yamada Y, Kagimoto S, Kubota A et al. Cloning, functional expression and pharmacological characterization of a fourth (hSSTR4) and a fifth (hSSTR5) human somatostatin receptor subtype. Biochem Biophys Res Commun 1993; 195: 844-852.

*26. Reubi JC, Schar JC, Waser B et al. Affinity profiles for human somatostatin receptor subtypes SSTI-SST5 of somatostatin radiotracers selected for scintigraphic and radiotherapeutic use. Eur J Nucl Med 2000; 27: 273-282.

27. Hofland LJ, Lamberts SWJ, van Hagen PM et al. Crucial role for somatostatin receptor subtype 2 in determining the uptake of [IIIIn-DTPA-D-Phel] J Nucl Med 2003; 44: I3I5-132I.

28. John M, Meyerhof W, Richter D et al. Positive somatostatin receptor scintigraphy correlates with the presence of somatostatin receptor subtype 2. Gut 1996; 38: 33-39.

29. Kwekkeboom DJ, Bakker WH, Kooij PP et al. [I 77Lu-DOTAOTyr3]octreotate: comparison with [I I I InDTPAo]octreotide in patients 200I; 28: 1319-1325.

30. Anthony LB, Woltering EA, Espenan GD et al. Indium-III-pentetreotide prolongs survival in gastroenteropancreatic malignancies. Semin Nucl Med 2002; 32: 123-132.

3I. Buscombe JR, Caplin ME \& Hilson AJ. Long-term efficacy of high-activity I I I in-pentetreotide therapy in patients with disseminated neuroendocrine tumors. J Nucl Med 2003; 44: I-6.

32. Slooter GD, Breeman WA, Marquet RL et al. Anti-proliferative effect of radiolabelled octreotide in a metastases model in rat liver. Int J Cancer 1999; 81 : 767-77I.

*33. Otte A, Mueller-Brand J, Dellas S et al. Yttrium-90-labelled somatostatin-analogue for cancer treatment. Lancet 1998; 35 I: 4I7-418.

34. Waldherr C, Pless M, Maecke HR et al. The clinical value of [90Y-DOTA]-DPhel-Tyr3-octreotide (90YDOTATOC) in the treatment of neuroendocrine tumours: a clinical phase II study. Ann Oncol 200 I; I 2: 94I-945.

35. Waldherr C, Schumacher T, Macke HR et al. Does tumor response depend on the number of treatment sessions at constant injected dose using 90Yttrium-DOTATOC in neuroendocrine tumors? Eur J Nucl Med 2002; 29: SI00. (abstract).

36. Chinol M, Bodei L, Cremonesi M \& Paganelli G. Receptor-mediated radiotherapy with Y-DOTA-DPheTyr-octreotide: the experience of the European Institute of Oncology Group. Semin Nucl Med 2002; 32: $|4|-147$.

37. Paganelli G, Bodei L, Handkiewicz Junak D et al. 90Y-DOTA-D-Phel-Try3-octreotide in therapy of neuroendocrine malignancies. Biopolymers 2002; 66: 393-398.

38. Paganelli G, Zoboli S, Cremonesi M et al. Receptor-mediated radiotherapy with 90Y-DOTA-D-Phe I-Tyr3octreotide. Eur J Nucl Med 2001; 28: 426-434.

39. Bodei L, Cremonesi M, Zoboli S et al. Receptor-mediated radionuclide therapy with 90Y-DOTATOC in association with amino acid infusion: a phase I study. Eur J Nucl Med Mol Imaging 2003; 30: 207-2I6.

40. Bodei L, Cremonesi M, Grana C et al. Receptor radionuclide therapy with (90)Y-[DOTA](0)-Tyr(3)octreotide ((90)Y-DOTATOC) in neuroendocrine tumours. Eur J Nucl Med Mol Imaging 2004; 3 I: I0381046.

4I. Valkema R, Pauwels S, Kvols L et al. Long-term follow-up of a phase I study of peptide receptor radionuclide therapy (PRRT) with (90Y-DOTA0,Tyr3)octreotide in patients with somatostatin receptor positive tumours. Eur J Nucl Med 2003; 30(supplement 2): S232. (abstract).

42. Valkema $R$, Pauwels $S$, Kvols $L$ et al. Survival in patients with neuroendocrine tumors after treatment with [90Y-DOTA,Tyr) in a phase-I study. J Nucl Med 2003; 44(supplement 2): I36P.

43. Baum RP, Soldner J, Schmucking M \& Niesen A. Intravenous and intra-arterial peptide receptor radionuclide therapy (PRRT) using Y-90-DOTA-Tyr3-octreotate (Y-90-DOTA-TATE) in patients with metastatic neuroendocrine tumors. Eur J Nucl Med 2004; 3 I (supplement 2): S238. (abstract).

44. Baum RP, Söldner J, Schmüching M \& Niesen A. Peptidrezeptorvermittelte Radiotherapie (PRRT) neuroendokriner Tumoren Klinischen Indikationen und Erfahrung mit 90Yttrium-markierten Somatostatinanaloga. Der Onkologe 2004; I0: 1098-1 II0. 
45. Kwekkeboom DJ, Bakker WH, Teunissen J et al. Treatment with Lu-I77-DOTA-Tyr3-octreotate in patients with neuroendocrine tumors: interim results. Eur J Nucl Med Mol Imaging 2003; 30(supplement 2): S23I. (abstract).

*46. Kwekkeboom DJ, Teunissen JJ, Bakker WH et al. Radiolabelled somatostatin analog [I77Lu-DOTAO, Tyr3] octreotate in patients with endocrine gastro entero pancreatic tumors. J Clin Oncol 2005; 23: 27542762.

47. Valkema R, Kvols L, Jamar F et al. Phase I study of therapy with 90Y-SMT487 (OctreoTher) in patients with somatostatin receptor (SS-R) positive tumors. J Nucl Med 2002; 43(supplement): 33P. (abstract).

48. Otte A, Herrmann R, Heppeler A et al. Yttrium-90 DOTATOC: first clinical results. Eur J Nucl Med I999; 26: 1439-1447.

49. Bakker WH, Krenning EP, Reubi JC et al. In vivo application of [I I I ln-DTPA-D-Phe I]-octreotide for detection of somatostatin receptor-positive tumors in rats. Life Sci 1991; 49: I593-I60I.

50. Krenning EP, Bakker WH, Kooij PP et al. Somatostatin receptor scintigraphy with indium-I I I-DTPA-DPhe-I-octreotide in man: metabolism, dosimetry and comparison with iodine-123-Tyr-3-octreotide. J Nucl Med 1992; 33: 652-658.

5I. Emami B, Lyman J, Brown A et al. Tolerance of normal tissue to therapeutic irradiation. Int J Radiat Oncol Biol Phys 1991; 21 : 109-122.

52. Moll S, Nickeleit V, Mueller-Brand J et al. A new cause of renal thrombotic microangiopathy: yttrium 90 DOTATOC internal radiotherapy. Am J Kidney Dis 200I; 37: 847-85I.

53. Cybulla M, Weiner SM \& Otte A. End-stage renal disease after treatment with 90Y-DOTATOC. Eur J Nud Med 200I; 28: I552-I554.

54. Stoffel MP, Pollok M, Fries J \& Baldamus CA. Radiation nephropathy after radiotherapy in metastatic medullary thyroid carcinoma. Nephrol Dial Transplant 200I; I6: 1082-I083.

55. Barone R, Borson-Chazot F, Valkema $\mathrm{R}$ et al. Patient-specific dosimetry in predicting renal toxicity with 90Y-DOTATOC: relevance of kidney volume and dose rate in finding a dose-effect relationship. J Nucl Med 2005; 46: 99S-106S.

56. Valkema R, Pauwels SA, Kvols LK et al. Long-term follow-up of renal function after peptide receptor radiation therapy with 90Y-DOTA0,Tyr3-octreotide and 177Lu-DOTA0, Tyr3-octreotate. J Nucl Med 2005; 46: 83S-9IS.

57. de Jong M, Rolleman EJ, Bernard BF et al. Inhibition of renal uptake of indium- I I-DTPA-octreotide in vivo. J Nucl Med 1996; 37: 1388-1392.

58. Jamar F, Barone R, Mathieu I et al. 86Y-DOTA0)-D-Phel-Tyr3-octreotide (SMT487)-a phase I clinical study: pharmacokinetics, biodistribution and renal protective effect of different regimens of amino acid co-infusion. Eur J Nucl Med Mol Imaging 2003; 30: 510-518.

59. Rolleman EJ, Valkema $R$, de Jong $M$ et al. Safe and effective inhibition of renal uptake of radiolabelled octreotide by a combination of lysine and arginine. Eur J Nucl Med Mol Imaging 2003; 30: 9-I5.

60. Barone R, Pauwels S, De Camps J et al. Metabolic effects of amino acid solutions infused for renal protection during therapy with radiolabelled somatostatin analogues. Nephrol Dial Transplant 2004; 19: 2275-228I.

6I. Bushnell D, Menda Y, Madsen M et al. Assessment of hepatic toxicity from treatment with 90 Y-SMT 487 (OctreoTher(TM)) in patients with diffuse somatostatin receptor positive liver metastases. Cancer Biother Radiopharm 2003; I 8: 58I-588.

62. Toth-Fejel S \& Pommier RF. Relationships among delay of diagnosis, extent of disease, and survival in patients with abdominal carcinoid tumors. Am J Surg 2004; 187: 575-579.

63. de Jong M, Kwekkeboom D, Valkema R \& Krenning EP. Radiolabelled peptides for tumour therapy: current status and future directions. Plenary lecture at the EANM 2002. Eur J Nucl Med Mol Imaging 2003; 30: 463-469.

64. Sanders C, Egger M, Donovan J et al. Reporting on quality of life in randomised controlled trials: bibliographic study. BMJ (Clin Res Ed.) 1998; 31 7: II91-1 194.

65. Bushnell D, O'Dorisio T, Menda Y et al. Evaluating the clinical effectiveness of 90Y-SMT 487 in patients with neuroendocrine tumors. J Nucl Med 2003; 44: I556-I560.

66. Teunissen JJ, Kwekkeboom DJ \& Krenning EP. Quality of life in patients with gastroenteropancreatic tumors treated with [I77Lu-DOTA0,Tyr3]octreotate. J Clin Oncol 2004; 22: 2724-2729.

67. Wild D, Schmitt JS, Ginj M et al. DOTA-NOC, a high-affinity ligand of somatostatin receptor subtypes 2, 3 and 5 for labelling with various radiometals. Eur J Nucl Med Mol Imaging 2003; 30: I338-I347. 
616 J. J. M. Teunissen et al

68. Béhé M, Pusken M, Henzel M et al. Upregulation of gastrin and somatostatin receptor after irradiation. Eur J Nucl Med 2003; 44(supplement 2): S218. (abstract).

69. Reubi JC \& Waser B. Concomitant expression of several peptide receptors in neuroendocrine tumours: molecular basis for in vivo multireceptor tumour targeting. Eur J Nucl Med Mol Imaging 2003; 30: $781-793$.

70. van Putten JWG, Price A, van der Leest AHD et al. A phase I study of gemcitabine with concurrent radiotherapy in stage III, locally advanced non-small cell lung cancer. Clin Cancer Res 2003; 9: 24722477. 